\title{
An algorithm as a diagnostic tool for central ocular motor disorders, also to diagnose rare disorders
}

\author{
Ludwig Kraus ${ }^{1 *}$ (D), Olympia Kremmyda ${ }^{1}$, Tatiana Bremova-Ertl ${ }^{1,2}$, Sebastià Barceló ${ }^{3}$, Katharina Feil ${ }^{1}$ and \\ Michael Strupp ${ }^{1}$
}

\begin{abstract}
Background: Recently an increasing number of digital tools to aid clinical work have been published. This study's aim was to create an algorithm which can assist physicians as a "digital expert" with the differential diagnosis of central ocular motor disorders, in particular in rare diseases.

Results: The algorithm's input consists of a maximum of 60 neurological and oculomotor signs and symptoms. The output is a list of the most probable diagnoses out of 14 alternatives and the most likely topographical anatomical localizations out of eight alternatives. Positive points are given for disease-associated symptoms, negative points for symptoms unlikely to occur with a disease. The accuracy of the algorithm was evaluated using the two diagnoses and two brain zones with the highest scores. In a first step, a dataset of 102 patients (56 males, $48.0 \pm 22$ yrs) with various central ocular motor disorders and underlying diseases, with a particular focus on rare diseases, was used as the basis for developing the algorithm iteratively. In a second step, the algorithm was validated with a dataset of 104 patients (59 males, $46.0 \pm 23$ yrs). For 12/14 diseases, the algorithm showed a sensitivity of between 80 and $100 \%$ and the specificity of 9/14 diseases was between 82 and 95\% (e.g., 100\% sensitivity and 75.5\% specificity for Niemann Pick type C, and 80\% specificity and $91.5 \%$ sensitivity for Gaucher's disease). In terms of a topographic anatomical diagnosis, the sensitivity was between 77 and 100\% for 4/8 brain zones, and the specificity of 5/8 zones ranged between 79 and 99\%.
\end{abstract}

Conclusion: This algorithm using our knowledge of the functional anatomy of the ocular motor system and possible underlying diseases is a useful tool, in particular for the diagnosis of rare diseases associated with typical central ocular motor disorders, which are often overlooked.

Keywords: Ocular motor disorder, Algorithm, Niemann pick type C, Gaucher's disease type 3, Ataxia teleangiectasia, Ataxia with oculomotor apraxia, Progressive supranuclear palsy, Wernicke encephalopathy

\section{Background}

Clinical practice shows that the diagnosis of rare diseases and central ocular motor disorders is often difficult, even for neurologists. On the other hand, we do have detailed knowledge on the anatomy, physiology and pathophysiology of ocular motor disorders, which allows a precise topographic anatomical diagnosis based on bedside examination even without any

\footnotetext{
* Correspondence: Ludwig-kraus@gmx.de

'Department of Neurology and German Center for Vertigo and Balance Disorders, Ludwig-Maximilians University, Munich, Campus Grosshadern, Marchioninistr. 15, 81377 Munich, Germany

Full list of author information is available at the end of the article
}

laboratory examinations [1] (see Table 3 for a short description of the most important parts of the clinical oculomotor examination). This means that, on the basis of clinical information, we can determine whether there is an impairment in the midbrain, pons, medulla or the cerebellar flocculus, nodulus, vermis, or fastigial nucleus.

Rare diseases, such as Niemann-Pick type C (NPC) [2], Tay-Sachs (TS) or Gaucher's disease type 3 (GD 3), are often overlooked, although the diagnosis can often be made on the basis of the patient history and clinical examination and confirmed by genetic testing. Several of

(c) The Author(s). 2019 Open Access This article is distributed under the terms of the Creative Commons Attribution 4.0 International License (http://creativecommons.org/licenses/by/4.0/), which permits unrestricted use, distribution, and reproduction in any medium, provided you give appropriate credit to the original author(s) and the source, provide a link to the Creative Commons license, and indicate if changes were made. The Creative Commons Public Domain Dedication waiver (http://creativecommons.org/publicdomain/zero/1.0/) applies to the data made available in this article, unless otherwise stated. 
these diseases are characterized by quite specific ocular motor findings, such as a supranuclear saccade or - at a later stage of the disease - gaze palsy in NPC and TS (for reference see [1]). From a therapeutic point of view, these diseases should also not be overlooked because several of them are treatable nowadays $[3,4]$.

Facing these problems, we designed a simple and easyto-use algorithm to help clinicians to correctly diagnose central ocular motor disorders and, in particular, associated rare diseases. Similar approaches have been recently used to diagnose cerebellar ataxias [5] or vertigo and dizziness [6].

\section{Methods}

The algorithm was created in three steps.

\section{Step one}

Two lists were designed: list A contained 14 diseases which often present with ocular motor disorders, list B contained 60 signs and symptoms typically found in these diseases. The latter can be subdivided into two major groups: general and ocular motor signs and symptoms (see Additional file 1).

Subsequently a table with list A in the cross column and list $\mathrm{B}$ in the along column was developed. Based on the current literature $[1,7,8]$, we linked the symptoms to the diseases by simply entering "Yes" if the symptom occurs with the disease and "No" if it does not.

By including various diseases, we wanted to give a representative clinical overview. Of course, the onset varies greatly depending on the etiology. In terms of imaging, even MRI of the brainstem might be normal within the first $72 \mathrm{~h}$ after symptom onset [9], which makes a systematic clinical examination and topographic diagnosis even more relevant. We included the following 14 different diseases: Niemann-Pick disease type C (NPC) $[10,11]$, ataxia teleangiectasia (AT) $[12-14]$, ataxia with oculomotor apraxia 1 and 2 (AOA 1,2) [15], Gaucher's disease type 3 (GD 3) [16, 17], Tay-Sachs disease (TS) [18], Wernicke encephalopathy [19, 20], Huntington's chorea [21], multiple sclerosis (MS) [22, 23], Parkinsonian syndromes [24], progressive supranuclear palsy (PSP) [25], tumor, infarction/hemorrhage, inflammatory encephalitis and various cerebellar syndromes (the latter term sums up diseases which are not a single point on our list A but cause a cerebellar syndrome like the spinocerebellar ataxias, CANVAS (Cerebellar ataxia with neuropathy and vestibular areflexia [26]) and Chiari malformation).

The basic working principle of the algorithm was to create a score for all of the 14 diseases as an output following the input of a patient's signs and symptoms. The symptoms are entered into an entry mask with "Yes" if the patient suffers from a symptom, "No" if he does not and "0" if a symptom was not tested or not testable (see Additional file 3).

The algorithm was further improved by increasing the strength of the linking of very typical symptoms to certain diseases. In the above-mentioned table we entered not "Yes" but "HR" for "highly related". If this symptom occurred, two points instead of one were added to a disease's score. We implemented this linking with, e.g., "internuclear ophthalmoplegia, aged < 60 years" and "MS", "vertical saccade palsy" and "NPC", "resting tremor" and "Parkinsonian syndromes". We also implemented a negative linking meaning that if a certain symptom occurs, the score of a disease was decreased. If, for instance, "paresis" occurs, the score of "NPC" and "GD3" is decreased by two points to better differentiate it from "TS".

\section{Step two}

The first version of the algorithm was improved using the data from 102 patients ( 56 males, $48.0 \pm 22$ yrs., distribution of the diseases: NPC - 7, AT - 5, AOA1,2-5, GD3-7, TS - 5, Wernicke encephalopathy - 5, Huntington's chorea - 6, MS - 10, Parkinson syndromes - 9, PSP - 9, tumor - 4, infarction/hemorrhage - 9, inflammatory encephalitis - 5, various cerebellar syndromes - 16). Most of these patients had been examined at our University Hospital in the past, independently of this study $[3,17]$. We went through the documented oculomotor examinations and looked for patients who fulfilled our criteria. There were two inclusion criteria: 1 . they had to be diagnosed with one and only one of the diseases in list A, and 2. they had to have oculomotor disorders which were found and described exactly in the documentation of the examination. The following exclusion criterion applied: patients had not to have had a second condition causing oculomotor disorder, such as brain surgery or a stroke in the past.

We put the clinical findings from these patients into the entry mask of the algorithm and evaluated its output. Then we adjusted the algorithm in an iterative way until we reached a good sensitivity and specificity. The arithmetic procedures we used in the algorithm were adding zero, one, two, three or four points to the score or subtracting one, two or three points.

\section{Step three}

This was a repetition of step two without further adjustment of the algorithm. We tested if similar results could be reproduced with a second cohort of 104 patients (59 males, $46.0 \pm 23$ yrs., distribution of the diseases: NPC 10, AT - 5, AOA1,2-4, GD3-10, TS - 5, Wernicke encephalopathy - 5, Huntington's chorea - 5, MS - 10, Parkinson syndromes - 10, PSP - 10, tumor - 4, infarction/ hemorrhage - 11, inflammatory encephalitis - 5, various cerebellar syndromes - 10). 
We used the same approach as described above to make the algorithm produce a suggestion on the topographical anatomical localization of the lesion. List $B$ with the symptoms remained exactly the same, while list A with the diseases was changed into a list of brain zones, which, when affected, result in ocular motor disorders. Again we used current literature to link the symptoms to the eight zones: midbrain, pons, medulla oblongata, basal ganglia, frontoparietal cortex and the three parts of the cerebellum flocculus/paraflocculus, vermis/fastigial nucleus and nodulus/uvula [8] (see Additional file 2).

We postulated three rules for interpreting the algorithm's result for the diseases: 1 . The result consists of the two diseases which get the highest scores in the output list (see Additional file 4). This can be more than two diseases if several get the same score. 2. If the algorithm provides more than five diseases as the result, we considered this as not helpful. When calculating the diseases' sensitivity and specificity we counted such results as false negatives for the actual disease and as false positives for the other 13 diseases. 3. If one disease's score was at least three points higher than any other score, this disease was considered as the only result of the algorithm. When the correct diagnosis appeared in the above-defined result of the algorithm consisting of one to five diseases we counted the result as a true positive for the actual disease and a true negative for the other diseases that did not appear in the result. Every incorrect one of the one to five result-diseases was counted as a false positive.

To interpret the algorithm's result for the topographic anatomical location we also postulated three rules similar to but not identical to the rules for the disease: 1 . The result consists of the two brain zones which get the highest scores in the algorithm's output list. This can be more than two zones if several get the same score. 2 . Every score with only one point or less is ignored unless one point is the highest existing score. 3 . If the algorithm provides more than four zones as a result, we considered this as not helpful and treated it as mentioned above. The sensitivity and specificity were calculated in the same way as for the diseases described above.

Approval from the ethics committee board of the University of Munich was obtained for the study. All investigations were conducted according to the principles of the Declaration of Helsinki.

\section{Statistical analysis}

For the statistical evaluation, the software "SAS" v9.3 was used. We calculated the confidence limits of the sensitivity/specificity using an asymptotic normal approximation to the binomial distribution. The whole algorithm was then embedded in an easy-to-use web tool which can be seen in Fig. 1 (called ADOC - Algorithm for the Diagnosis of OCulomotor disorders).

\section{Results}

As mentioned in Methods, the algorithm to diagnose the affected brain structures and diseases was developed in an iterative way. In the following, the sensitivity and specificity are given for the last version.

\section{First ("testing") cohort}

In the testing cohort, the sensitivity for the brain zones lay between 90 and $0 \%$ (best: frontoparietal cortex $90 \%$, basal ganglia $80 \%$, flocculus/paraflocculus $75 \%$ ). The specificity was between 98 and 49\% (frontoparietal cortex and nodulus/uvula 98\%, basal ganglia 96\%; and pons $49 \%)$.

For the diseases, the sensitivity ranged from 100\% (NPC, AT, AOA1 and 2, GD 3, TS, PSP, Wernicke's encephalopathy, inflammatory encephalitis, infarction /hemorrhage) to $75 \%$ (tumor).

As our result design consists of at least two suggestions about the underlying disease in most cases, there was at least one false positive in every output. So, as expected, the specificity was not as high, ranging from 96 to 63\% (best: infarction/hemorrhage and Parkinsonian syndromes 96\%, Wernicke's encephalopathy 95\%; and MS 63\%).

\section{Second ("validation") cohort}

The sensitivity and specificity of diseases and brain zones from the validation cohort can be seen in Tables 1 and 2 respectively. For the brain zones, the sensitivity ranged from 100 to $0 \%$ (medulla oblongata $100 \%$, pons $82 \%$, basal ganglia 79\%). The specificity was between 99 and $52 \%$ (frontoparietal cortex $99 \%$, nodulus/ uvula $98 \%$, medulla oblongata $84 \%$; and midbrain $52 \%$ ).

For the diseases, the sensitivity ranged from 100 (NPC, AOA1 and 2, TS, Wernicke's encephalopathy, inflammatory encephalitis, infarction/hemorrhage) to 60\% (AT). The specificity was between 95 and 66\% (Parkinsonian syndromes and Huntington's chorea 95\%, GD 3 92\%; and inflammatory encephalitis 66\%). In general, the results of the validation cohort were slightly worse than in the testing cohort, with the biggest difference being the sensitivity for AT (5/5 vs. $3 / 5)$ (Table 3$)$.

\section{Discussion}

The major findings of this study are as follows:

First, this algorithm can be a helpful tool for diagnosing, in particular, rare diseases associated with central ocular motor disorders. For example, in the validation cohort we reached a sensitivity of $100 \%$ for NPC (10/10) and Wernicke's encephalopathy (5/5). It is 


\section{Oculomotor Algorithm}

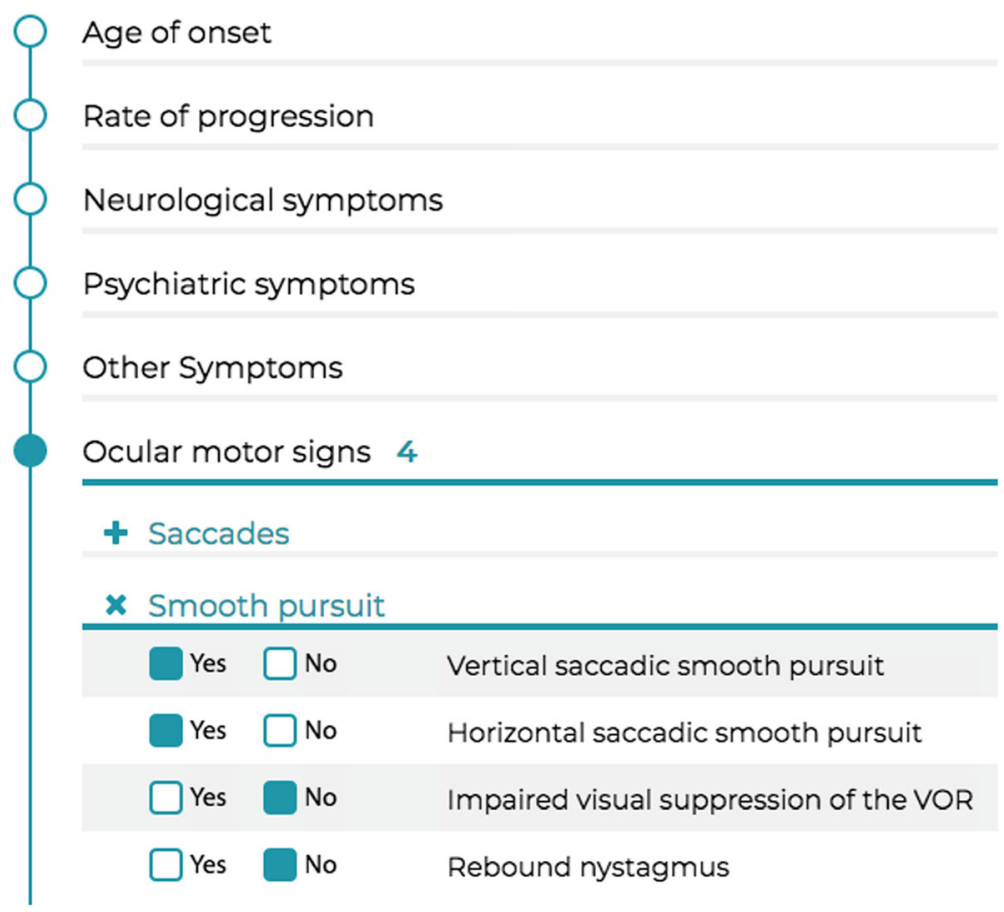

Fig. 1 Screenshot of the data entry mask in the finished web tool. This excerpt shows the main signs and symptoms categories of the data entry file. By clicking on "Yes" or "No" one confirms or denies a symptom. Symptoms that were not tested can just be skipped by not clicking on any of the possibilities and leaving the field empty

Table 1 Sensitivity and specificity for the diseases in the validation cohort. Sensitivity ranged from 100\% for NPC, AOA1 and 2, TS, Wernicke's encephalopathy, inflammatory encephalitis, infarction/hemorrhage to 60\% for AT. Specificity was between 95\% for Parkinsonian syndromes and Huntington's chorea and 66\% for inflammatory encephalitis. Additionally the $95 \%$ confidence interval was calculated for every value

\begin{tabular}{|c|c|c|c|c|c|c|c|}
\hline & $\begin{array}{l}\text { Niemann-Pick disease } \\
\text { Type C (NP-C) }\end{array}$ & $\begin{array}{l}\text { Inflammatory } \\
\text { Encephalitis }\end{array}$ & Tumor & $\begin{array}{l}\text { Infarction/ } \\
\text { hemorrhage }\end{array}$ & $\begin{array}{l}\text { Multiple } \\
\text { sclerosis }\end{array}$ & $\begin{array}{l}\text { Parkinsonian } \\
\text { syndromes }\end{array}$ & $\begin{array}{l}\text { Progressive } \\
\text { supranuclear palsy } \\
\text { (PSP) }\end{array}$ \\
\hline \multirow[t]{2}{*}{ Sensitivity: } & $10 / 10$ & $5 / 5$ & $3 / 4$ & $11 / 11$ & $8 / 10$ & $8 / 10$ & $8 / 10$ \\
\hline & $100 \%$ & $100 \%$ & $75.0 \%$ & $100 \%$ & $80.0 \%$ & $80.0 \%$ & $80.0 \%$ \\
\hline $95 \% \mathrm{Cl}$ & $1.000-1.000$ & $1.000-1.000$ & $0.326-1.000$ & $1.000-1.000$ & $0.552-1.000$ & $0.552-1.000$ & $0.552-1.000$ \\
\hline \multirow{2}{*}{ Specificity: } & $71 / 94$ & $65 / 99$ & $82 / 100$ & $82 / 93$ & $63 / 94$ & $89 / 94$ & $83 / 94$ \\
\hline & $75.5 \%$ & $65.7 \%$ & $82.0 \%$ & $88.2 \%$ & $67.0 \%$ & $94.7 \%$ & $88.3 \%$ \\
\hline \multirow[t]{2}{*}{$95 \% \mathrm{Cl}$} & $0.668-0.842$ & $0.563-0.750$ & $0.745-0.895$ & $0.816-0.947$ & $0.575-0.765$ & $0.901-0.992$ & $0.818-0.948$ \\
\hline & $\begin{array}{l}\text { Wernicke's } \\
\text { encephalo-pathy }\end{array}$ & $\begin{array}{l}\text { Ataxia } \\
\text { teleangiectasia }\end{array}$ & $\begin{array}{l}\text { Ataxia with } \\
\text { oculomotor apraxia } \\
1 / 2\end{array}$ & $\begin{array}{l}\text { Gaucher's } \\
\text { disease } \\
\text { Type } 3 \text { (GD3) }\end{array}$ & $\begin{array}{l}\text { Huntington's } \\
\text { chorea (HTT) }\end{array}$ & $\begin{array}{l}\text { Cerebellar } \\
\text { syndromes }\end{array}$ & Tay-Sachs disease \\
\hline \multirow[t]{2}{*}{ Sensitivity: } & $5 / 5$ & $3 / 5$ & $4 / 4$ & $8 / 10$ & $4 / 5$ & $10 / 10$ & $5 / 5$ \\
\hline & $100 \%$ & $60.0 \%$ & $100 \%$ & $80.0 \%$ & $80.0 \%$ & $100 \%$ & $100 \%$ \\
\hline $95 \% \mathrm{Cl}$ & $1.000-1.000$ & $0.171-1.000$ & $1.000-1.000$ & $0.552-1.000$ & $0.449-1.000$ & $1.000-1.000$ & $1.000-1.000$ \\
\hline \multirow{2}{*}{ Specificity: } & $89 / 99$ & $86 / 99$ & $78 / 100$ & $86 / 94$ & $94 / 99$ & 79/94 & 78/99 \\
\hline & $89.9 \%$ & $86.9 \%$ & $78.0 \%$ & $91.5 \%$ & $94.5 \%$ & $84.0 \%$ & $78.8 \%$ \\
\hline $95 \% \mathrm{Cl}$ & $0.840-0.958$ & $0.802-0.935$ & $0.699-0.861$ & $0.858-0.971$ & $0.906-0.993$ & $0.766-0.914$ & $0.707-0.868$ \\
\hline
\end{tabular}


Table 2 Sensitivity and specificity for the brain zones in the validation cohort. Sensitivity ranged from 100\% for medulla oblongata to $0 \%$ for nodulus/uvula. Specificity was between $99 \%$ for frontoparietal cortex and 52\% for midbrain. Additionally the $95 \%$ confidence interval was calculated for every value

\begin{tabular}{|c|c|c|c|c|c|c|c|c|}
\hline & Midbrain & Pons & $\begin{array}{l}\text { Medulla } \\
\text { oblongata }\end{array}$ & $\begin{array}{l}\text { Flocculus/ } \\
\text { Paraflocculus }\end{array}$ & $\begin{array}{l}\text { Vermis/ Fastigial } \\
\text { Nucleus }\end{array}$ & $\begin{array}{l}\text { Nodulus/ } \\
\text { Uvula }\end{array}$ & $\begin{array}{l}\text { Basal } \\
\text { Ganglia }\end{array}$ & $\begin{array}{l}\text { Fronto- parietal } \\
\text { Cortex }\end{array}$ \\
\hline \multirow[t]{2}{*}{ Sensitivity: } & $30 / 39$ & $28 / 34$ & $4 / 4$ & $34 / 54$ & $14 / 54$ & $0 / 54$ & $22 / 28$ & $5 / 11$ \\
\hline & $76.9 \%$ & $82.4 \%$ & $100 \%$ & $63.0 \%$ & $25.9 \%$ & $0.0 \%$ & $78.6 \%$ & $45.5 \%$ \\
\hline $95 \% \mathrm{Cl}$ & $\begin{array}{l}0.637- \\
0.901\end{array}$ & $\begin{array}{l}0.695- \\
0.952\end{array}$ & $1.000-1.000$ & $0.501-0.758$ & $0.142-0.376$ & $0.000-0.000$ & $\begin{array}{l}0.634- \\
0.938\end{array}$ & $0.160-0.749$ \\
\hline \multirow[t]{2}{*}{ Specificity: } & $30 / 58$ & $34 / 63$ & 78/93 & $25 / 43$ & $34 / 43$ & $42 / 43$ & $57 / 69$ & $85 / 86$ \\
\hline & $51.7 \%$ & $54.0 \%$ & $83.9 \%$ & $58.1 \%$ & $79.1 \%$ & $97.7 \%$ & $82.6 \%$ & $98.8 \%$ \\
\hline $95 \% \mathrm{Cl}$ & $\begin{array}{l}0.389- \\
0.646\end{array}$ & $\begin{array}{l}0.417- \\
0.663\end{array}$ & $0.764-0.913$ & $0.434-0.729$ & $0.669-0.912$ & $0.932-1.000$ & $\begin{array}{l}0.737- \\
0.916\end{array}$ & $0.966-1.000$ \\
\hline
\end{tabular}

Table 3 Different aspects of the clinical oculomotor examination. This table contains a short description of the most important parts of the clinical oculomotor examination and the possible pathologies which should be looked for

\begin{tabular}{|c|c|}
\hline Type of examination & Question \\
\hline \multicolumn{2}{|l|}{ Inspection } \\
\hline Head/body posture & Tilt or turn of head/body \\
\hline Position of eyelids & Ptosis \\
\hline \multicolumn{2}{|l|}{ Eye position/motility } \\
\hline \multirow[t]{2}{*}{ Position of eyes during straight-ahead gaze } & $\begin{array}{l}\text { Misalignment in primary position, } \\
\text { spontaneous or fixation nystagmus }\end{array}$ \\
\hline & Horizontal or vertical misalignment \\
\hline \multicolumn{2}{|l|}{ Cover/Uncover test } \\
\hline Examination of eyes in eight positions (binocular and monocular) & $\begin{array}{l}\text { Determination of range of motility, gaze-evoked nystagmus } \\
\text { (GEN), end-point nystagmus, sustained, unsustained }\end{array}$ \\
\hline \multicolumn{2}{|l|}{ Gaze-holding function } \\
\hline $10-40^{\circ}$ in the horizontal & $\begin{array}{l}\text { GEN: } \\
\text { horizontal, also important for the } \\
\text { diagnosis of downbeat nystagmus }\end{array}$ \\
\hline $10-20^{\circ}$ in the vertical & vertical \\
\hline Back to $0^{\circ}$ after $30 \mathrm{~s}$ & rebound nystagmus \\
\hline \multicolumn{2}{|l|}{ Slow smooth pursuit movements } \\
\hline Horizontal and vertical & Smooth or saccadic \\
\hline \multicolumn{2}{|l|}{ Saccades } \\
\hline $\begin{array}{l}\text { Horizontal and vertical when looking around or at targets; important } \\
\text { to note: upper eye must be lifted when examining vertical saccades }\end{array}$ & Latency, velocity, accuracy, conjugacy \\
\hline \multicolumn{2}{|l|}{ Optokinetic nystagmus (OKN) } \\
\hline Horizontal and vertical with OKN drum or tape & Inducible, direction, phase (reversal or monocularly diagonal) \\
\hline \multicolumn{2}{|l|}{ Peripheral vestibular function } \\
\hline $\begin{array}{l}\text { Head-impulse test (HIT) for the examination of the VOR (Halmagyi-Curthoys } \\
\text { test): rapid turning of the head and fixation of a stationary target; nowadays } \\
\text { better to be done by the video-HIT }\end{array}$ & Unilateral or bilateral peripheral vestibular deficit \\
\hline \multicolumn{2}{|l|}{ Fixation suppression of the VOR } \\
\hline Turning the head and fixation of a target moving at same speed & Impairment of fixation suppression of the VOR \\
\hline \multicolumn{2}{|l|}{ Examination with Frenzel's or the M-glasses [27] } \\
\hline Straight-ahead gaze, to the right, to the left, downward and upward & $\begin{array}{l}\text { Peripheral vestibular spontaneous nystagmus } \\
\text { versus central fixation nystagmus }\end{array}$ \\
\hline Head-shaking test & Head-shaking nystagmus \\
\hline
\end{tabular}


assumed that both of them are vastly underdiagnosed $[11,19]$. Since these diseases are treatable or, in the case of Wernicke's encephalopathy, even curable, an early diagnosis has a huge impact on the outcome of these patients.

Second, the results for the brain zones were generally worse but can still give an indication of where to look for pathologies in imaging. In the validation cohort, the sensitivity for involvement of the medulla oblongata was $100 \%(4 / 4)$ and for the pons $82.4 \%(28 / 34)$.

Third, the algorithm can be applied in less than $5 \mathrm{~min}$.

Compared to "medx" [6], a similar tool recently published to diagnose vertigo and dizziness, our algorithm showed a higher sensitivity (medx: 40 to $80.5 \%$ ) but a lower specificity (medx: at least $80 \%$ ). This can perhaps be explained by the fact that "medx" focuses on the first suggested diagnosis, whereas our tool presents the two top-scoring results. Since our algorithm deals with more rare diseases, the different approaches seem to be suitable for the different problems they are supposed to solve. Another recent algorithm to diagnose recessive ataxias is called "RADIAL" [5]. It showed a higher average sensitivity and specificity (RADIAL: 92.2 and $95.4 \%$, respectively) than our tool but it works with around twice as many features (120 vs. 60).

This study has several limitations: First, it was a retrospective analysis. Second, our gold standard was the diagnosis made in the hospital, which is not flawless. Third, a major problem was that the affected brain zones could not always be verified in the brain imaging available or that patients had multiple lesions as in MS. Regarding the cerebellum, imaging often shows no pathologies, however the clinical signs are often specific based on current knowledge of the function and dysfunction of the flocculus/paraflocculus, nodulus, nucleus fastigii and dorsal vermis. All in all, however, the major focus was on the diagnosis of rare diseases which can evidently be improved by such a simple algorithm.

\section{Conclusions}

In summary, this algorithm uses our knowledge on the functional anatomy of the ocular motor system. It is based on the simple idea of comparing signs and symptoms typical of certain diseases and brain lesions to signs and symptoms occurring in a certain patient. It is a useful tool for diagnosing diseases, in particular rare ones, which present with central ocular motor disorders.

\section{Additional files}

Additional file 1: Workflow of the algorithm - diseases. These tables show the working principle of the algorithm using the example of 5 of the 14 diseases (MS, PSP, Wernicke's encephalopathy, AT, NPC). Whenever a symptom occurs in a patient whether the disease's score is increased or decreased depends on the type of linking: $N E V=-3$, OTTD $=-2$, $\mathrm{UL}=-1, \mathrm{~N}=+0, \mathrm{Y}=+1, \mathrm{HR}=+2$. (DOCX $28 \mathrm{~kb}$ )

Additional file 2: Workflow of the algorithm - brain zones. These tables show the working principle of the algorithm using the example of 4 of the 8 brain zones (midbrain, pons, medulla, flocculus/paraflocculus). Whenever a symptom occurs in a patient, whether the brain zone's score is increased depends on the type of linking: $N=+0, R=+1, H R=+2$. (DOCX $20 \mathrm{~kb}$ )

Additional file 3: Data entry mask with 3 examples. These tables show three sample patients' signs and symptoms entered in the algorithm's entry mask. "Yes" means the symptom was present, "No" means it was not and " 0 " it was not looked for in the examination. The real diagnoses are:1 = PSP, 2 = Wernicke's Encephalopathy, 3 = NPC. (DOCX 24 kb)

Additional file 4: Output of the algorithm for the input of the 3 examples from Additional file 3. According to our result interpretation rules (see Methods), the algorithm's diagnosis suggestions for the three patients are: Patient 1: brain zone: Basal ganglia and pons; disease: PSP. Patient 2: brain zone: Pons, medulla oblongata, flocculus/paraflocculus and vermis/fastigial nucleus; disease: Wernicke's encephalopathy, MS and inflammatory encephalitis. Patient 3: brain zone: Midbrain, basal ganglia; disease: NPC. The real diagnoses are: $1=$ PSP, $2=$ Wernicke's Encephalopathy, 3 = NPC. (DOCX $16 \mathrm{~kb})$

\section{Abbreviations}

ADOC: Algorithm for the diagnosis of oculomotor disorders; AOA 1,2: Ataxia with oculor motor apraxia type 1 and 2; AT: Ataxia teleangiectasia; CANVAS: Cerebellar ataxia with neuropathy and vestibular areflexia; GD3: Gaucher's disease type 3; MS: Multiple sclerosis; NPC: Niemann-Pick disease type C; PSP: Progressive supranuclear palsy; TS: Tay-Sachs disease

\section{Acknowledgements}

We thank Katie Göttlinger for copy-editing this manuscript

This work was supported by the German Ministry of Education and Research (BMBF), Grant No. $01 \mathrm{EO} 0901$ to the German Center for Vertigo and Balance Disorders (IFBLMU).

\section{Authors' contributions}

MS, LK, OK, Department of Neurology and German Center for Vertigo and Balance Disorders (DSGZ), Ludwig-Maximilians University, Munich, Campus Grosshadern, Munich, Germany (Michael.Strupp@med.uni-muenchen.de): conception of the study, acquisition and interpretation of the data, drafting the manuscript. TB-E, Department of Neurology and German Center for Vertigo and Balance Disorders (DSGZ), Ludwig-Maximilians University, Munich, Campus Grosshadern, Munich, Germany: examination of patients and acquisition of the data with rare diseases. KF, Department of Neurology and German Center for Vertigo and Balance Disorders (DSGZ), LudwigMaximilians University, Munich, Campus Grosshadern, Munich, Germany: examination of patients. SB, Syntax for Science: statistical analysis and interpretation of the data. All authors read and approved the final manuscript.

\section{Funding}

This study was supported by Actelion Pharmaceuticals Ltd. which paid for the statistical analysis by Syntax for Science and the creation of the web tool by ICON Worldwide.

Availability of data and materials

All data are available from the corresponding authors on request.

Ethics approval and consent to participate

Approval from the ethics committee board of the University of Munich was obtained for the study. All investigations were conducted according to the principles of the Declaration of Helsinki.

Consent for publication

Not applicable. 


\section{Competing interests}

L. Kraus, O. Kremmyda and K. Feil do not declare any conflicts of interest. T. Bremova-Ertl received speaker's honoraria from Actelion and SanofiGenzyme.S. Barceló performed statistical analyses paid for by Actelion Pharmaceuticals.

M. Strupp is Joint Chief Editor of the Journal of Neurology, Editor in Chief of Frontiers of Neuro-otology and Section Editor of F1000. He has received speaker's honoraria from Abbott, Actelion, Auris Medical, Biogen, Eisai, Grünenthal, GSK, Henning Pharma, Interacoustics, Merck, MSD, Otometrics, Pierre-Fabre, TEVA, UCB. He is a shareholder of IntraBio. He acts as a consultant for Abbott, Actelion, AurisMedical, Heel, IntraBio and Sensorion.

\section{Author details}

${ }^{1}$ Department of Neurology and German Center for Vertigo and Balance Disorders, Ludwig-Maximilians University, Munich, Campus Grosshadern, Marchioninistr. 15, 81377 Munich, Germany. ${ }^{2}$ Department of Neurology, Inselspital, University Hospital Bern, Bern, Switzerland. ${ }^{3}$ Syntax for Science, Parc Bit, Edif. Disset A2, 07121 Palma de Mallorca, Spain.

Received: 2 November 2018 Accepted: 22 July 2019

Published online: 08 August 2019

\section{References}

1. Leigh RJ, Zee DS. The neurology of eye movements. 5th ed. Oxford: Oxford University Press; 2015.

2. Patterson MC, Clayton P, Gissen P, Anheim M, Bauer P, Bonnot O, et al. Recommendations for the detection and diagnosis of Niemann-Pick disease type C: an update. Neurol Clin Pract. 2017;7(6):499-511.

3. Bremova T, Malinova V, Amraoui Y, Mengel E, Reinke J, Kolnikova M, et al. Acetyl-dl-leucine in Niemann-Pick type C: a case series. Neurology. 2015;85(16):1368-75.

4. Patterson MC, Vecchio D, Jacklin E, Abel L, Chadha-Boreham H, Luzy C, et al. Long-term miglustat therapy in children with Niemann-Pick disease type C. J Child Neurol. 2010;25(3):300-5.

5. Renaud M, Tranchant C, Martin JVT, Mochel F, Synofzik M, van de Warrenburg $B$, et al. A recessive ataxia diagnosis algorithm for the next generation sequencing era. Ann Neurol. 2017:82(6):892-9.

6. Feil K, Feuerecker R, Goldschagg N, Strobl R, Brandt T, von Müller A, et al. Predictive capability of an iPad based medical device $(\operatorname{medx})$ for the diagnosis of vertigo and dizziness. Front Neurol. 2018;9:29.

7. Thömke F. Augenbewegungsstörungen. 3rd ed. Bad Honnef: Hippocampus Verlag; 2016.

8. Strupp M, Kremmyda O, Adamczyk C, Böttcher N, Muth C, Yip C, et al. Central ocular motor disorders, including gaze palsy and nystagmus. J Neurol. 2014;261(2):542-58.

9. Saber Tehrani AS, Kattah JC, Kerber KA, Gold DR, Zee DS, Urrutia VC, et al. Diagnosing stroke in acute dizziness and vertigo: pitfalls and pearls. Stroke. 2018:49(3):788-95.

10. Patterson MC, Mengel E, Wijburg FA, Muller A, Schwierin B, Drevon $\mathrm{H}$, et al. Disease and patient characteristics in NP-C patients: findings from an international disease registry. Orphanet J Rare Dis. 2013;8(1):12.

11. Vanier MT, Gissen P, Bauer P, Coll MJ, Burlina A, Hendriksz CJ, et al. Diagnostic tests for Niemann-Pick disease type C (NP-C): a critical review. Mol Genet Metab. 2016;118(4):244-54.

12. Rothblum-Oviatt C, Wright J, Lefton-Greif MA, McGrath-Morrow SA, Crawford TO, Lederman HM. Ataxia telangiectasia: a review. Orphanet J Rare Dis. 2016;11(1):159.

13. Gatti R, Perlman S. Ataxia-Telangiectasia. In: Adam MP, Ardinger HH, Pagon RA, Wallace SE, Bean $L H$, Mefford HC, et al., editors. GeneReviews(R). Seattle: University of Washington, Seattle; 1993.

14. Teive HA, Moro A, Moscovich M, Arruda WO, Munhoz RP, Raskin S, et al. Ataxia-telangiectasia - a historical review and a proposal for a new designation: ATM syndrome. J Neurol Sci. 2015;355(1-2):3-6.

15. Jayadev S, Bird TD. Hereditary ataxias: overview. Genet Med. 2013;15(9):673-83.

16. Benko W, Ries M, Wiggs EA, Brady RO, Schiffmann R, FitzGibbon EJ. The saccadic and neurological deficits in type 3 Gaucher disease. PLoS One. 2011;6(7):e22410.

17. Bremova-Ertl T, Schiffmann R, Patterson M, Belmatoug N, Billette de Villemeur T, Bardins $S$, et al. Oculomotor and vestibular findings in Gaucher disease type 3 and their correlation with neurological abnormalities. Front Neurol. 2018;8:711.
18. Neudorfer O, Pastores GM, Zeng BJ, Gianutsos J, Zaroff CM, Kolodny EH. Late-onset Tay-Sachs disease: phenotypic characterization and genotypic correlations in 21 affected patients. Genet Med. 2005;7(2):119.

19. Galvin R, Bråthen G, Ivashynka A, Hillbom M, Tanasescu R, Leone M. EFNS guidelines for diagnosis, therapy and prevention of Wernicke encephalopathy. Eur J Neurol. 2010;17(12):1408-18.

20. Zubaran C, Fernandes J, Rodnight R. Wernicke-Korsakoff syndrome. Postgrad Med J. 1997;73(855):27-31.

21. Lasker AG, Zee DS. Ocular motor abnormalities in Huntington's disease. Vis Res. 1997;37(24):3639-45.

22. Servillo G, Renard D, Taieb G, Labauge P, Bastide S, Zorzon M, et al. Bedside tested ocular motor disorders in multiple sclerosis patients. Mult Scler Int. 2014;2014. Article ID 732329.

23. Lizak N, Clough M, Millist L, Kalincik T, White OB, Fielding J. Impairment of smooth Pursuit as a Marker of early Multiple sclerosis. Front Neurol. 2016;7:206.

24. Anderson TJ, MacAskill MR. Eye movements in patients with neurodegenerative disorders. Nat Rev Neurol. 2013;9(2):74.

25. Termsarasab P, Thammongkolchai T, Rucker JC, Frucht SJ. The diagnostic value of saccades in movement disorder patients: a practical guide and review. J Clin Mov Disord. 2015;2(1):14.

26. Szmulewicz DJ, Roberts L, McLean CA, MacDougall HG, Halmagyi GM, Storey E. Proposed diagnostic criteria for cerebellar ataxia with neuropathy and vestibular areflexia syndrome (CANVAS). Neurol Clin Pract. 2016;6(1):61-8.

27. Strupp M, Fischer C, Hanß L, Bayer O. The takeaway Frenzel goggles: a Fresnel-based device. Neurology. 2014;83(14):1241-5.

\section{Publisher's Note}

Springer Nature remains neutral with regard to jurisdictional claims in published maps and institutional affiliations.
Ready to submit your research? Choose BMC and benefit from:

- fast, convenient online submission

- thorough peer review by experienced researchers in your field

- rapid publication on acceptance

- support for research data, including large and complex data types

- gold Open Access which fosters wider collaboration and increased citations

- maximum visibility for your research: over $100 \mathrm{M}$ website views per year

At BMC, research is always in progress.

Learn more biomedcentral.com/submissions 